\title{
Is green space in the living environment associated with people's feelings of social safety?
}

\section{Jolanda Maas, Peter Spreeuwenberg}

NIVEL, Netherlands Institute for Health Services Research, PO Box 1568, 3500 BN Utrecht, The Netherlands; e-mail: j.maas@nivel.nl, p.spreeuwenberg@nivel.nl

\section{Marijke Van Winsum-Westra}

ALTERRA, Green World Research, PO Box 47, 6700 AA Wageningen, The Netherlands; e-mail: marijke.vanwinsum@wur.nl

\section{Robert A Verheij}

NIVEL, Netherlands Institute for Health Services Research, PO Box 1568, 3500 BN Utrecht, The Netherlands; e-mail: r.verheij@nivel.nl

\section{Sjerp de Vries}

ALTERRA, Green World Research, PO Box 47, 6700 AA Wageningen, The Netherlands; e-mail: sjerp.devries@wur.nl

\section{Peter P Groenewegen}

NIVEL, Netherlands Institute for Health Services Research, PO Box 1568, 3500 BN Utrecht, The Netherlands; e-mail: p.groenewegen@nivel.nl; also Utrecht University, Department of Human Geography and Department of Sociology, Utrecht, The Netherlands

Received 26 March 2008; in revised form 23 June 2008; published online 18 December 2008

\begin{abstract}
The authors investigate whether the percentage of green space in people's living environment affects their feelings of social safety positively or negatively. More specifically they investigate the extent to which this relationship varies between urban and rural areas, between groups in the community that can be identified as more or less vulnerable, and the extent to which different types of green space exert different influences. The study includes 83736 Dutch citizens who were interviewed about their feelings of social safety. The percentage of green space in the living environment of each respondent was calculated, and data analysed by use of a three-level latent variable model, controlled for individual and environmental background characteristics. The analyses suggest that more green space in people's living environment is associated with enhanced feelings of social safety-except in very strongly urban areas, where enclosed green spaces are associated with reduced feelings of social safety. Contrary to the common image of green space as a dangerous hiding place for criminal activity which causes feelings of insecurity, the results suggest that green space generally enhances feelings of social safety. The results also suggest, however, that green space in the most urban areas is a matter of concern with respect to social safety.
\end{abstract}

\section{Introduction}

There is increasing attention being paid towards and evidence for a positive relationship between the amount of green space in people's living environment and people's health. Several studies have shown that a more natural living environment is positively related to people's self-perceived health and lower mortality risks (de Vries et al, 2003; Maas et al, 2006; Mitchell and Popham, 2007; Nielsen and Hansen, 2007; Takano et al, 2002); but there might be another side to this coin, as natural spaces are also often regarded as unsafe places. In this paper, therefore, we investigate the relationship between the availability of green space and people's feelings of safety.

\section{Feelings of social safety}

Feeling safe is a prerequisite for well-being, quality of life, and good health (ChiviteMatthews and Maggs, 2002; Green et al, 2002). Safety can be judged both objectively (safety measured by facts and figures) and subjectively (perceived safety experienced by the individual) (Van Winsum-Westra and De Boer, 2004). In this paper we are 
concerned with subjective social safety. Social safety refers to safety resulting from human behaviour and interactions between people in public space (Van WinsumWestra and De Boer, 2004). Objective social safety may differ from subjective social safety but, in terms of behavioural constraints, it is subjective safety which influences behaviour and which causes people to avoid places they associate with insecurity.

Both individual as well as neighbourhood characteristics affect feelings of social safety. Some environments feel safer than others (Hale et al, 1994). The role of green space appears ambiguous, however. On the one hand, green space can be perceived as dangerous because it may facilitate crime by providing a hiding place for perpetrators of crime and may conceal criminal activity (Herzog and Flynn-Smith, 2001; Van Winsum-Westra and De Boer, 2004). On the other hand, studies from the US suggest that exposure to some types of natural environments may actually enhance feelings of social safety in a neighbourhood, because green space can reduce feelings of anger, frustration, and aggression, as well as increase surveillance (Kuo and Sullivan, 2001a; 2001b). The aim of this present study is to investigate whether green space positively or negatively affects feelings of social safety. In addition to investigating the general relationship, we also examine whether this relation varies between urban and rural areas and between different population categories (men/women, old/young). These issues are explained more specifically and hypotheses are formulated in the next section.

\section{Level of urbanisation}

Urban and rural areas constitute different kinds of environments in which to examine feelings of social safety. Rural areas are more sparsely populated, have a different population (fewer young adults, one-person households, and ethnic minorities, for example), and are often seen as harmonious, peaceful, tranquil, closely knit communities with lots of green space (Little et al, 2005; Steenbekkers et al, 2006; Valentine, 1997) than urban areas. As a consequence, rural areas are usually regarded as being safer than urban areas (Francis, 1999; Little et al, 2005; Oppelaar and Wittebrood, 2006). Urban green spaces are often regarded as unsafe, due to the allegedly poorer standard of maintenance (Jorgensen et al, 2002), and because they can provide potential hiding places for criminals (Herzog and Chernick, 2000; Nasar and Fisher, 1993; Nasar et al, 1993).

Thus, the reduced feelings of safety and the higher crime rates in urban settings, combined with our expectation that the nature of rurality will positively influence the way people living in these areas experience their feelings of safety, led to the following hypothesis.

Hypothesis 1: People living in urban areas with more green space will feel less safe than people living in rural areas with more green space.

\section{Vulnerable population groups}

Little is known about whether the relationship between green space and feelings of social safety varies between population groups. Nor is it known whether the more vulnerable population groups in society feel less safe with more green space nearby. Literature on feelings of social safety in green environments has shown that women, the elderly, and members of ethnic minorities in particular feel unsafe in green environments (Van Winsum-Westra and De Boer, 2004). Women mainly fear sexual assault; the safety concerns of the elderly are heightened by their perceived frailty, reduced mobility, and sense of vulnerability; and the safety concerns of members of ethnic minorities are mainly related to fear of racial aggression (eg Burgess, 1988; Jorgensen and Anthopoulou, 2007; Jorgensen et al, 2002; Koskela, 1997; Koskela and Pain, 2000; 
Madge, 1997). Safety concerns are often a major factor limiting the use of green urban spaces and woodlands (Burgess, 1988; Madge, 1997).

This leads to the following hypothesis.

Hypothesis 2: Women, elderly people, and members of ethnic minorities feel less safe in green environments than do other population groups.

\section{Type of green space}

Another relevant issue is the type of green space. Several studies have shown that 'open' green space (green spaces which preserve visibility) increases feelings of social safety, as opposed to 'closed' green space (green spaces that do not preserve visibility), due to the higher visibility of potential dangers (Hanyu, 2000; Herzog and Chernick, 2000; Herzog and Flynn-Smith, 2001; Herzog and Kutzli, 2002; Jorgensen et al, 2002; Kuo et al, 1998; Kuo and Sullivan, 2001b; Müderrisoglu and Demir, 2004). This leads to the following hypothesis.

Hypothesis 3: Open green spaces are positively related to feelings of social safety, whereas closed green spaces are negatively related to feelings of social safety.

Most research on the relationship between green space and feelings of social safety uses qualitative methods and tends to focus on specific green spaces, such as local parks or forests in local settings (eg Hanyu, 2000; Herzog and Chernick, 2000; Herzog and Kutzli, 2002; Jorgensen et al, 2002). On the basis of a systematic search in Web of Science we can conclude that this is the first quantitative study to focus on the relationship between the amount of green space in the living environment and feelings of social safety. Quantitative studies can improve our understanding of general patterns and differences between subgroups of the population. They can improve the basis for informed policy making, can identify people and places for in-depth studies, and they can also place locally specific qualitative research in a more general context.

\section{Methods}

\section{Data}

We used four different datasets for the purposes of this study. The data on feelings of social safety were taken from the Police Population Monitor National Report (PMB, 2001) ( $N=88607$; nonresponse $28 \%)$.

This is a nationwide representative telephone survey commissioned by the Netherlands Ministry of the Interior and Kingdom Relations and the Ministry of Justice. It is conducted every two years among a randomly selected sample of approximately 90000 people and focuses on differences in crime rates, feelings of social safety, and opinions on the police (PMB, 2001).

Environmental data were derived from the National Land Cover Classification database (LGN4), which lists the dominant type of land use for each $25 \times 25 \mathrm{~m}$ grid cell in the Netherlands for the year 2001 (de Wit and Clevers, 2004). A $25 \times 25 \mathrm{~m}$ grid cell is only regarded as 'green space' if the cell is dominated by green space. As a consequence, smaller green areas, such as trees along a road or small bushes situated near built-up areas are not regarded as green space.

The availability of green space is our main variable of interest. However, there may be other environmental factors that also affect social safety. Data on these other environmental factors were derived from Statistics Netherlands and from the Living Environment Database of the Netherlands Ministry of Spatial Planning and the Environment, and related to the years 2001 and 1998 (in some cases). All were measured at four-digit postcode level. 
The four different datasets were geographically linked on the basis of four-digit postcodes. The Netherlands is divided into 4000 four-digit postcodes. A four-digit postcode in the Netherlands represents an average of 1772 households; these postcodes often correspond to neighbourhoods in urban areas, whereas they sometimes represent a whole village in rural areas. Only respondents with no missing data (83736) were included in the analysis.

\section{Measures}

Data at the individual level

Feelings of social safety The dependent variable in our analyses is a measure of feelings of social safety experienced in the general population. People were asked to answer the following questions about their feelings of social safety.

- How often do you feel unsafe?

- How often do you avoid places, because you think they are unsafe?

- How often do you not open the door at night because you think it is unsafe?

- How often do you leave valuable things at home because you are afraid they will get stolen outside?

- How often do you make a detour to avoid unsafe places?

The first question is a general one about people's feelings of social safety, whereas the other four are concerned with people's actual behaviour on account of their feelings of insecurity. The answers that could be given were: "often" (1); "sometimes" (2); or never (3). Thus, a higher score meant that people felt safer. The data were used to construct a scale for feelings of social safety in a multilevel model. The internal consistency of the scale at the individual level depends on the degree of intercorrelation among the items and the number of items on the scale (Raudenbush et al, 1991) and ranges from 0 to 1 , as does Cronbach's $\alpha$. The internal consistency of the scale at individual level was 0.92, which indicates that it is a good scale. Each item contributes differently to the scale of social safety and they were therefore taken into account as control variables in the model.

Demographic and socioeconomic characteristics of respondents The following demographic and socioeconomic characteristics of the respondents were taken into account, because they could potentially affect feelings of social safety: gender (male $=0$; female $=1$ ); age (divided into four categories: $15-25,26-45,46-65$, and $65+$ years); ethnicity $(0=$ native Dutch; 1 = ethnic minority); highest level of completed education (as an ordinal variable); work situation ( $0=$ paid job; $1=$ no job); and living in an owner-occupied or rented home (owner-occupied home $=0$; rented home $=1$ ). The last three variables were included to control for the socioeconomic status of the individual. People with a lower socioeconomic status often feel less safe because they feel economically unprotected against the consequences of becoming a victim (Luymes and Tamminga, 1995; Oc and Tiesdell, 1997). The distribution of these characteristics is shown in table 1.

\section{Data at postcode level}

Green space Information on the percentages of green space was derived from the LGN 4 database. This database distinguishes thirty-nine categories of land use, including crop types, forest types, water, grass areas, various built-up areas, railways, and main roads, and is a database which has proven to be valid, accurate, and reliable (de Wit and Clevers, 2004; Thunissen and de Wit, 2000).

The total percentage of green space was calculated for each four-digit postcode sector, and included all urban green, agricultural green, forest, and nature conservation areas. 
Table 1. Percentage distribution, or mean (with standard deviation shown in parentheses) of characteristics of the study population $(n=83736)$.

\begin{tabular}{|c|c|}
\hline Demographic characteristics & \\
\hline $\begin{array}{l}\text { Gender } \\
\text { female }(\%)\end{array}$ & 53 \\
\hline $\begin{array}{l}\text { female }(\%) \\
\text { male }(\%)\end{array}$ & 47 \\
\hline Age (years) & \\
\hline $26-45(\%)$ & 8.3 \\
\hline $46-65(\%)$ & 37.3 \\
\hline $65+(\%)$ & 33.8 \\
\hline $15-25(\%)$ & 20.6 \\
\hline Socioeconomic characteristics & \\
\hline Level of education (mean) & $4(1.8)$ \\
\hline Ethnic minority $(\%)$ & 3.4 \\
\hline Native Dutch (\%) & 97 \\
\hline Unemployed (\%) & 56.5 \\
\hline Employed (\%) & 43.5 \\
\hline Rented home $(\%)$ & 35.8 \\
\hline Owner-occupied home $(\%)$ & 64.2 \\
\hline Level of urbanisation & \\
\hline Very strongly urban (\%) & 15.4 \\
\hline Strongly urban $(\%)$ & 26.5 \\
\hline Moderately urban (\%) & 19.2 \\
\hline Rural area $(\%)$ & 34.2 \\
\hline
\end{tabular}

The National Landcover Classification Database distinguishes between open green spaces and closed green spaces. Open green spaces include grass areas, grass areas in built-up environments, open sand in costal areas, open dune vegetation, riparian areas, dune heath, and heath,. Closed green spaces include forests of all kinds (coniferous forests, deciduous forests) in built-up and non-built-up environments, and closed dune vegetation. Parts of a park that are characterised by grass areas are regarded as open green, for example, whereas parts of a park that are characterised by forest are regarded as closed green. Table 2 gives an overview of the mean percentages of green space at different levels of urbanisation. The level of urbanisation (high-low) was strongly positively related to the total percentage of green space $(r=0.73)$, but there is no excessive colinearity.

Measure of urbanisation The levels of urbanisation we used were based on the number of households per square kilometre within the municipality, and are widely used in the Netherlands (Den Dulk et al, 1999). The original classification consists of five categories: (1) very strongly urban (over 2500 addresses per km); (2) strongly urban

Table 2. Mean (with standard deviations shown in parentheses), minimum, and maximum percentages of green space in each level of urbanisation.

\begin{tabular}{|c|c|c|c|c|c|c|c|c|}
\hline & \multicolumn{2}{|c|}{ Very strongly urban } & \multicolumn{2}{|c|}{ Strongly urban } & \multicolumn{2}{|c|}{ Moderately urban } & \multicolumn{2}{|c|}{ Nonurban } \\
\hline & mean & $\min / \max$ & mean & $\min / \max$ & mean & $\min / \max$ & mean & $\min / \max$ \\
\hline Green & 17.6 & 0 & 33.6 & 0 & 55.2 & 1.45 & 78.4 & 2.96 \\
\hline space $(\%)$ & $(17.3)$ & 96.1 & (26.3) & 99.7 & $(24.3)$ & 98.6 & $(16.3)$ & 98.6 \\
\hline Open green & 10.1 & 0 & 25.2 & 0 & 42.2 & 0.4 & 68.4 & 1.1 \\
\hline space $(\%)$ & (13.3) & 96.1 & (23.2) & 97.8 & (23.4) & 96.4 & (19.6) & 97.5 \\
\hline Closed green & 7.4 & 0 & 8.4 & 0 & 13 & 0 & 9.9 & 0 \\
\hline space $(\%)$ & (8.4) & 42.8 & (11.6) & 90.1 & $(16.5)$ & 83.2 & (11.5) & 84.9 \\
\hline
\end{tabular}


(1500 - 2500 addresses per $\mathrm{km})$; (3) moderately urban (1000-1500 addresses per $\mathrm{km})$; (4) slightly urban (500-1000 addresses per $\mathrm{km}$ ); and (5) nonurban (fewer than 500 addresses per km). However, we grouped 'slightly urban' and 'nonurban' municipalities into one category for the purposes of this study; these two levels are often combined in the Netherlands to describe rural areas (LNV, 2004; Steenbekkers et al, 2006).

Aspects of the living environment that can cause feelings of social insecurity When investigating the relationship between feelings of social safety and the amount of green space in a person's living environment, it is important to rule out other environmental factors that could influence feelings of social safety. For example, people tend to feel less safe in environments with elevated crime rates. Crime rates are related to the relative size of the male population and to percentages of adolescents, young adults, and ethnic minory group members, that is, groups that are at higher risk of becoming offenders or victims of crime (South and Messner, 2000; Wilcox et al, 2003; Wittebrood and Oppelaar, 2005), this led us to include the percentage of females, the percentage of people aged 15-24 years, and the percentage of ethnic minority group members in the postcode area. Another part of the variation in crime levels is related to neighbourhood socioeconomic characteristics, such as concentrated poverty and residential instability (measured by levels of homeownership and residential mobility, respectively) (Sampson and Raudenbush, 1999). Both these characteristics of each postcode area were taken into account. Concentrated poverty was operationalised as the average gross monthly income of the households (in Euros). Residential stability was measured by the percentage of rented homes, as well as the number of households who moved within, to, or from the municipality per year, expressed as a percentage of the total number of households.

Research also indicates that there are some places which are empirically associated with high levels of crime, such as restaurants, bars or pubs, hotels, and areas with shopping centres (Eck and Weisburd, 1995); therefore we also included these environmental factors. The number of cafés, the number of hotels, and the number of restaurants were all measured per 100 households; shops were measured as a percentage of the number of units of real estate.

\section{Design/statistical analyses}

We explored seven variations of a three-level latent variable model in order to study the relationship between the amount of green space in people's living environment and their feelings of social safety. There were several reasons for this choice. A multilevel model was used in order to account for clustering within the different levels in the data. A three-level hierarchical model was used which distinguished between individuals nested within environments and responses to different scale items within individuals. This last level was included as an alternative to the more common solution of combining the item scores at the individual level into one indicator for social safety. Our method was considered a more appropriate way of measuring people's feelings of social safety, while using different items, because it generates an average score for feelings of social safety, controlling for individual and environmental characteristics, which increases reliability (Raudenbush, 2003)

In short, the first level of the model (item level) serves as a measurement model; it describes the linkage between the items of feelings of social safety and the latent true scores for each person. The regression coefficients of the items indicate to the extent to which the average score on the items deviates from the general average on the feelings of social safety scale. The coefficients cannot be interpreted the same way as the variables which have been taken into account at individual and postcode levels. 
The two highest levels of the model may be viewed as a two-level model predicting the latent true scores. At the second level (individual level), the true scores are the outcomes estimated at the individual level based on the scores on the individual items. This shows the variation between individuals within postcode areas. The third level shows the variance between postcode areas (Raudenbush and Sampson, 1999).

Likelihood ratio tests were used to compare the explanatory power of the more complicated model with the previous ones: the lower the value, the better the explanatory power. The estimates of the variables in the model are related to the average on the five items of the scale. The analyses were performed with MLwiN 2.0.

\section{Results}

\section{Green space and feelings of social safety}

The first model includes all background and control variables at individual and postcode levels. The percentage of green space was added in the second model, and the results show that the percentage of green space positively influences feelings of social safety: people who have more green space in their living environment feel safer (table 3).

Adding the percentage of green space to the model reduces the variance at the postcode level although the variance at individual level remains the same, which indicates that the relationship between the percentage of green space and feelings of social safety is the same for everybody living in the same postcode area. The effect of green space on feelings of social safety is more an environmental effect than an individual effect, which means that people will feel equally safe or unsafe in a postcode area with the same amount of green space, regardless of their gender or age. A comparison of the variance between model 1 and model 2 shows that green space explains $8.3 \%$ of the variance at postcode level that remained after controlling for all control variables at individual and postcode levels.

\section{Strength of the relationship}

The relationship between green space and feelings of social safety is relatively strong (model 2, see table 3). It is comparable with the relationship with the number of rented homes or the percentage of people in the postcode area aged 15-25 years (figure 1), both of which indicators are considered to be important factors influencing feelings of social safety (South and Messner, 2000). The effect of $10 \%$ more green space is approximately equal to that of $10 \%$ fewer rented homes and $5 \%$ fewer people aged $15-25$ years. Figure 1 shows the results from the regression models on the strength of the relationship between green space and people's feelings of social safety.

\section{Relationship between social safety and green space at different levels of urbanisation}

We used the third model to examine the relationship between the percentage of green space and feelings of social safety at each level of urbanisation (hypothesis 1).

Adding the relationship between the percentage of green space and feelings of social safety at each level of urbanisation significantly increased the explanatory power of the model. The difference between the $-2 \times \log$ likelihood $\chi^{2}$ values of model 2 and model 3 is 40 ( $\mathrm{df}=3, p<0.001)$, indicating that the relationship between green space and feelings of social safety should be considered in urban and rural context (table 3).

Model 3 shows that there is a significant positive relationship between green space and feelings of social safety at all levels of urbanisation, except in the very strongly urban areas. People tend to feel safer when they have more green space in their living environment, except in very strongly urban areas. In very strongly urban areas the amount of green space in people's living environment is negatively related to their 
Table 3. Effects of green space on feelings of safety by level of urbanisation, controlled for demographic and socioeconomic characteristics at individual and area levels: parameters, with standard errors shown in parentheses.

Feelings of social safety

model 1:

feelings of

social safety model 2:

total percentage

of green space model 3:

total percentage

of green space

per level of

urbanisation
Average feeling of social safety

Item level

Item 1: feeling unsafe in general

Item 2: avoiding places

Item 3: not opening the door at night

Item 4: leaving valuable things at home

Item 5: making a detour to avoid unsafe places

Individual level

Female

Male

Aged 26-45 years

Aged 46-65 years

Aged $65+$ years

Aged 15-25 years

Level of education

Ethnic minority

Native Dutch

Unemployed

Employed

Rented home

Owner-occupied home

Postcode level

People aged $15-24$ years $(\%)$

$\%$ women

$\%$ ethnic-minority group members

$\%$ rented homes

$\%$ of households who moved within, to, or from the municipality

Shops as a percentage of the total number of real estate units

Number of cafés per 100 households

Number of hotels per 100 households

Number of restaurants per 100 households

Average gross monthly income

Urbanisation

Very strongly urban

Strongly urban

Moderately urban

Rural areas

\section{Green space}

$\%$ green space

$\%$ green space in very strongly urban areas

$\%$ green space in strongly urban areas

$\%$ green space in moderately urban areas

$\%$ green space in rural areas

$$
2.622(0.002)^{* * *}
$$

$2.624(0.002)^{* * *}$

$2.614(0.003)^{* * *}$

reference category

$-0.1017(0.002) * * *$

$-0.1706(0.003)^{* * *}$

$-0.1812(0.003)^{* * *}$

$-0.1017(0.002) * * *$

$-0.1706(0.003)^{* * *}$

$-0.1017(0.002)^{* * *}$

$-0.680(0.003)^{* * *}$

$-0.1812(0.003)^{* * *}$

$-0.680(0.003)^{* * *}$

$-0.680(0.003)^{* * *}$

$-0.680(0.003) * * *$

$-0.237(0.003) * * *$

reference category

$0.023(0.006)^{* * *}$

$-0.009(0.006)$

$0.008(0.007)$

reference category

$-0.011(0.001)^{* * * *}$

-0.006 (0.008)

reference category

$-0.040(0.004)^{* * *}$

reference category

$-0.024(0.003) * * *$

$-0.237(0.003)^{* * *}$

$-0.237(0.003)^{* * *}$

$0.023(0.006)^{* * * *}$

$-0.009(0.006)$

$0.008(0.007)$

$0.023(0.006)^{* * *}$

$-0.009(0.006)$

$0.001(0.007)$

$-0.011(0.001)^{*}$

$-0.006(0.008)$

$-0.011(0.001)^{*}$

$-0.006(0.008)$

$-0.040(0.004)^{* * *}$

$-0.040(0.004)^{* * *}$

$-0.024(0.003)^{* * *}$

$-0.024(0.003) * * *$
$-0.004(0.0008) * * *$

$-0.008(0.001)^{* * *}$

$-0.004(0.0002) * * *$

$-0.0002(0.0001)$

$-0.563(0.110)^{* * *}$

$-0.243(0.046)^{* * *}$

$0.630(0.097)^{* * * *}$

$0.065(0.038)$

$-0.00001(0.000)^{* *}$

$-0.128(0.010) * * *$

$-0.139(0.007) * * *$

$-0.085(0.007) * * *$

reference category

$-0.003(0.0008)^{* * *}$

$-0.005(0.001) * * *$

$\begin{array}{ll}-0.004(0.0002)^{* * *} & -0.004(0.0002)^{* * *} \\ -0.0007(0.0002)^{* * *} & -0.0007(0.0002)^{* * *}\end{array}$

$-0.0001(0.0001) \quad-0.0001(0.0001)$

$-0.313(0.110)^{* * *}$

$-0.382(0.120) * * *$

$-0.243(0.046)^{* * * *}$

$-0.230(0.046) * * *$

$0.579(0.097) * * *$

$0.543(0.095) * * *$

$0.076(0.037)^{* * *}$

$0.069(0.038)$

$-0.00001(0.000)^{* *}$

$-0.00001(0.000)^{* *}$

$-0.135(0.018)^{* * * *}$

$0.090(0.010) * * *$

$-0.109(0.008)^{* * *}$

$-0.067(0.007)^{* * *}$

$-0.102(0.008) * * *$

$-0.062(0.007) * * *$

$0.001(0.0001)^{* * *}$

$-0.0002(0.0003)$

$0.001(0.0002) * * *$

$0.0008(0.0002)^{* * *}$

$0.002(0.0002)^{* * *}$ 
Table 3 (continued).

Feelings of social safety

model 1: feelings of social safety

\section{model 2:} total percentage of green space model 3:

total percentage of green space per level of urbanisation
-2 log-likelihood

Variance at postcode level

Variance at individual level

Variance at item level:

Item 1: feeling unsafe in general

Item 2: avoiding places

Item 3: not opening the door at night

Item 4: leaving valuable things at home

Item 5: making a detour to avoid unsafe places

$\begin{array}{lll}784090 & 784017 * * * & 783977 * * \\ 0.0036(0.0003) & 0.0033(0.0003) & 0.0032(0.0013) \\ 0.121(0.0009) & 0.121(0.0009) & 0.121(0.0013) \\ & & \\ 0.2159(0.0013) & 0.2159(0.0013) & 0.216(0.0013) \\ 0.2522(0.0015) & 0.2522(0.0015) & 0.2522(0.0013) \\ 0.4705(0.0025) & 0.4705(0.0025) & 0.4704(0.0013) \\ 0.4734(0.0025) & 0.4734(0.0025) & 0.4732(0.0013) \\ 0.2224(0.0013) & 0.2224(0.0013) & 0.2224(0.0013)\end{array}$

\section{0}

$0.0036(0.0003)$

$0.2159(0.0013)$

$0.2522(0.0015)$

$0.2224(0.0013)$

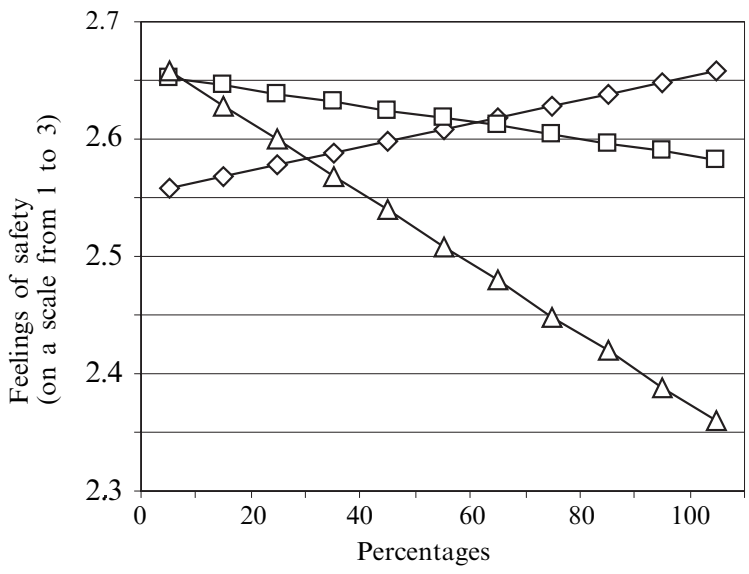

Figure 1. Feelings of social safety by percentage of green space, percentage of rented homes, and percentage of people aged between 15-25 years based on the three-level latent-variable model, model 2, controlled for demographic and socioeconomic characteristics at individual and area levels.

feelings of social safety, although the relation is not a significant one. Figure 2 shows the results from the regression models on the relationship between green space and people's feelings of social safety at the different levels of urbanisation.

\section{Vulnerable population groups and feelings of social safety}

It was hypothesised (hypothesis 2) that vulnerable population groups would feel less safe in green environments. We used models 4 and 5 (table 4) to examine the relationship between green space and feelings of social safety for men and women, and for different age groups, respectively. Contrary to our expectations, women with more green space in their living environment feel safer (model 4). In the very strongly urban areas, however, this relation is not significant. Feelings of social safety among men were generally unaffected by the amount of green space in the living environment (table 4). 


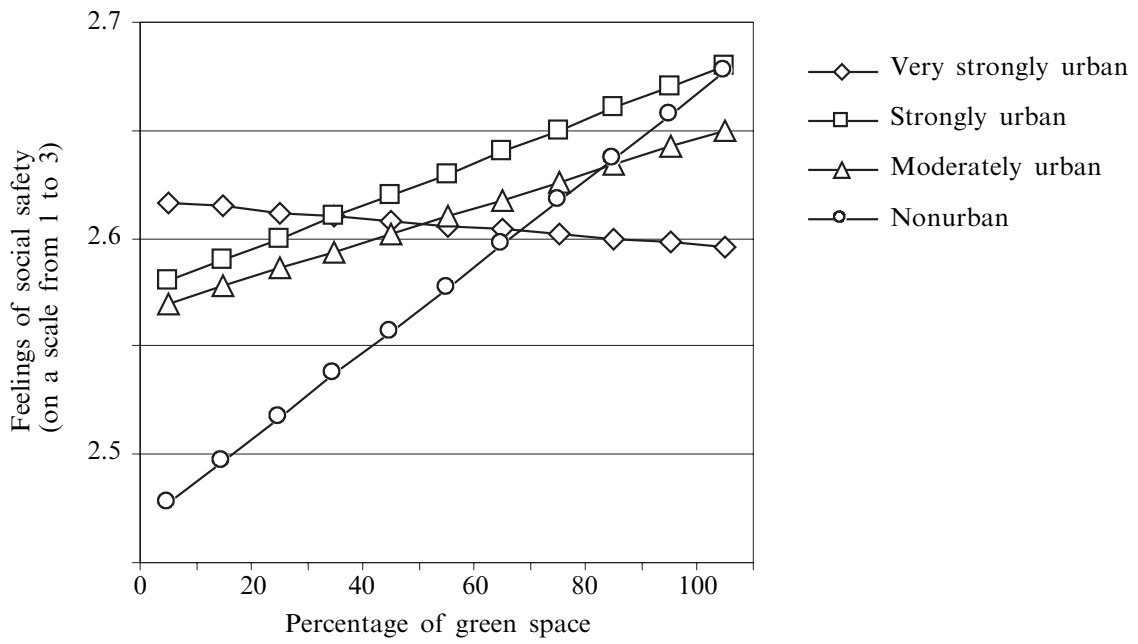

Figure 2. Feelings of social safety by percentage of green space for different levels of urbanisation, based on the three-level latent-variable model, model 3, controlled for demographic and socioeconomic characteristics at individual and area levels.

Table 4. Effects of green space on feelings of social safety by gender and age at different levels of urbanisation, controlled for demographic and socioeconomic characteristics at individual and area levels: parameters, with standard errors shown in parentheses.

Feelings of social safety

\begin{tabular}{llll}
\hline very strongly & strongly & moderately & rural areas \\
urban areas & urban areas & urban areas & \\
\hline
\end{tabular}

Model 4

$\%$ green space $\times$ female

$\begin{array}{llll}0.00008 & 0.0015 & 0.0013 & 0.0026 \\ (0.003) & (0.0002)^{* * *} & (0.0002)^{* * *} & (0.0003)^{* * *} \\ -0.0005 & 0.0004 & 0.0002 & 0.0004 \\ (0.0003) & (0.0002) & (0.0002) & (0.0002)\end{array}$

Model 5

$\%$ green space $\times$ people

-0.001
$(0.0004)^{* * *}$
-0.005
$(0.0003)$
0.0006
$(0.0003)$
-0.00003
$(0.0003)$

0.0002

0.0007

0.0001 aged 15-25

$\%$ green space $\times$ people aged 26-45

$\%$ green space $\times$ people aged $46-65$

(0.0003)

$(0.0005)$

$(0.0005)$

$\%$ green space $\times$ people

0.0009

0.0006

0.001

$(0.0002)^{* *}$

$(0.0002)^{* *}$

$(0.0003)^{* * *}$

0.001

0.001

0.002

aged $65+$

$(0.0002)^{* * *}$

$(0.0003)^{* * *}$

$(0.0003)^{* * *}$

0.0008

0.002

$* p \leqslant 0.05 ; * * \leqslant \leqslant 0.01 ; * * * p \leqslant 0.001$.

Again contrary to our expectations (model 5), elderly people feel safer when there is more green space in their living environment, except in the very strongly urban areas, where there is no such effect. Furthermore, people aged 15-25 years feel less safe in very strongly urban areas when there is more green space in their living environment (table 4).

\section{Type of green space}

It was hypothesised (hypothesis 3) that open green spaces are positively related to feelings of social safety, whereas closed green spaces are negatively related to feelings of social safety, hence the relation was analysed for different types of green spaces, 
taking the urban - rural setting of each type of green space into account. In models 6 and 7, we examined the relationship between open and closed green space respectively, and feelings of social safety (table 5).

The results of this analysis confirm our hypothesis and show a positive relationship between open green space in the living environment and feelings of social safety, except in the very strongly urban areas - where this relationship is absent (model 6).

Closed green space seems to be positively related to feelings of social safety, but not in the most urban areas, where closed green space is negatively related to feelings of social safety (table 5, model 7). Figures 3 and 4 show the results from the regression model for the relationship between open and closed green space, respectively, and people's feelings of social safety at different levels of urbanisation.

Table 5. The effect of the percentage of open or closed green space on feelings of social safety at different levels of urbanisation, controlled for demographic and socioeconomic characteristics at individual and area levels: parameters, with standard errors shown in parentheses.

\begin{tabular}{|c|c|c|}
\hline & \multicolumn{2}{|c|}{ Feelings of social safety } \\
\hline & $\begin{array}{l}\text { model } 6 \text { : } \\
\text { percentage of } \\
\text { open green space } \\
\text { per level of } \\
\text { urbanisation }\end{array}$ & $\begin{array}{l}\text { model } 7 \text { : } \\
\text { percentage of } \\
\text { closed green space } \\
\text { per level of } \\
\text { urbanisation }\end{array}$ \\
\hline $\begin{array}{l}\% \text { open green space in very strongly urban areas } \\
\% \text { open green space in strongly urban areas } \\
\% \text { open green space in moderately urban areas } \\
\% \text { open green space in rural areas }\end{array}$ & $\begin{array}{l}0.002(0.0004) \\
0.001(0.0002)^{* * *} \\
0.0008(0.0002)^{* * *} \\
0.002(0.0002)^{* * *}\end{array}$ & \\
\hline $\begin{array}{l}\% \text { closed green space in very strongly urban areas } \\
\% \text { closed green space in strongly urban areas } \\
\% \text { closed green space in moderately urban areas } \\
\% \text { closed green space in rural areas }\end{array}$ & & $\begin{array}{l}-0.0014(0.0007)^{*} \\
0.0009(0.0004)^{*} \\
0.010(0.0004)^{* *} \\
0.0010(0.0003)^{* * *}\end{array}$ \\
\hline
\end{tabular}

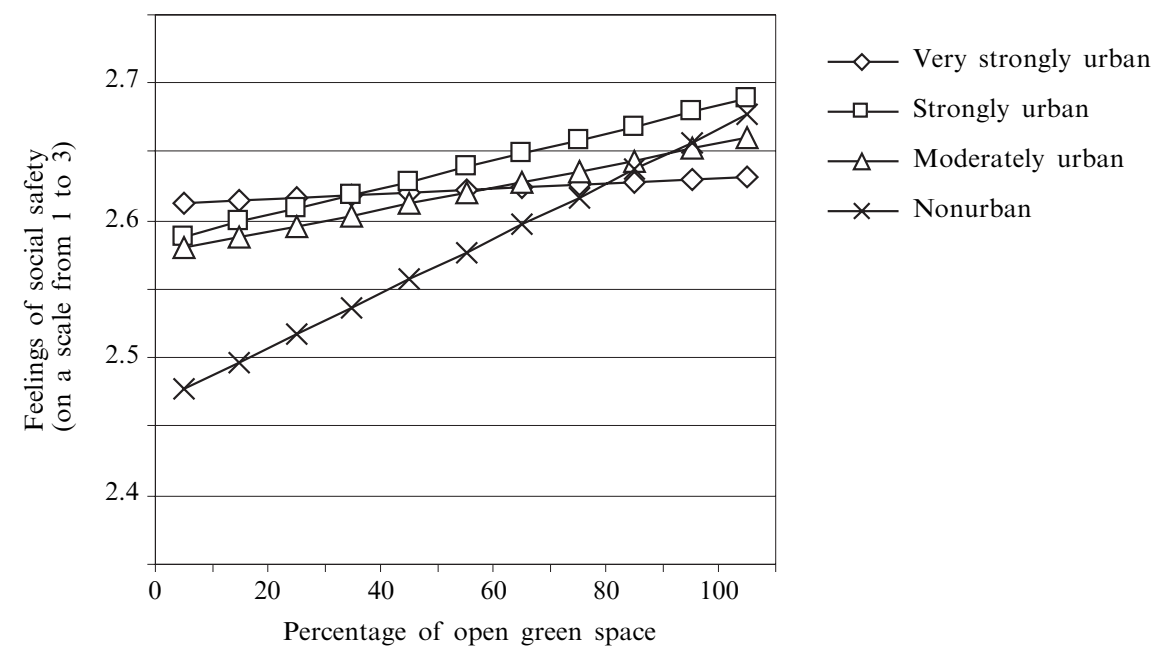

Figure 3. Feelings of social safety by percentage of open green space for different levels of urbanisation, based on the three-level latent-variable model, model 6, controlled for demographic and socioeconomic characteristics at individual and area levels. 


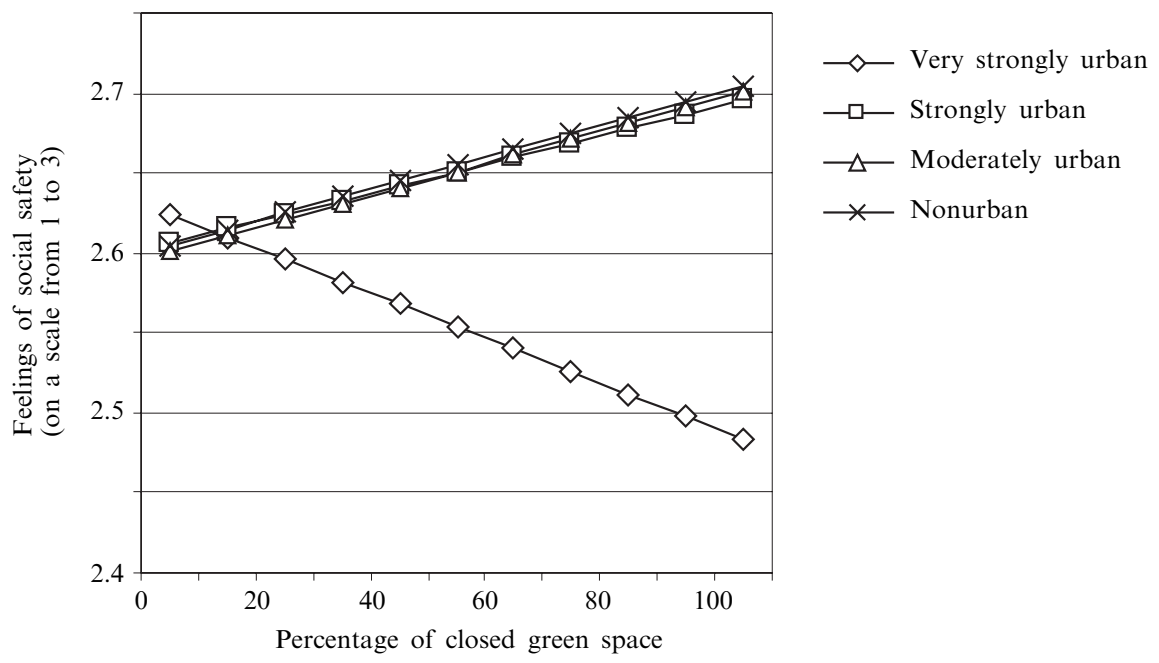

Figure 4. Feelings of social safety by percentage of closed green space for different levels of urbanisation, based on the three-level latent-variable model, model 7, controlled for demographic and socioeconomic characteristics at individual and area levels.

\section{Conclusion and discussion}

We have examined the relationship between the percentage of green space in the living environment and feelings of social safety. The results lead us to conclude that green space in people's living environment is generally associated with enhanced feelings of social safety. This relationship is concurrent with the positive relationship between green space and people's health that has been found in the literature. Closed green space was only found to increase feelings of insecurity in very strongly urban areas, a conclusion which has implications for spatial planning. Investing in green space not only makes people healthier, but also helps to make them feel safer.

In contrast to the findings of Kuo and Sullivan (2001b), we found that the positive relationship with social safety is not restricted to open green spaces in strongly urban areas, moderately urban areas, and rural areas. This may be due to differences in measurement and the interpretation of measurements in the Dutch setting. Spaces with trees were classified as 'closed' green spaces in our study, whereas spaces with trees which preserve visibility were classified as 'open' green space in Kuo and Sullivan's (2001b) study.

Although the results of this study have implications for spatial planning, further research is needed to translate some of the findings into clear-cut guidelines for decision making in urban planning. First, it is unknown why closed green spaces in very strongly urban areas are associated with increased feelings of insecurity, whereas they are associated with enhanced feelings of social safety at all other levels of urbanisation. This might be due to the size of buildings in very strongly urban areas with lots of green space: buildings in these areas are likely to be larger, higher, and more compact, which are building characteristics which are known to affect fear of crime (Newman and Franck, 1982). Furthermore, these increased feelings of insecurity might be associated with poorer levels of maintenance of green areas in very strongly urban areas. The maintenance of green spaces is important for people's feelings of social safety, and disorder in the form of graffiti, garbage, and vandalism diminishes feelings of social safety. These forms of disorder are more common in more urban areas (Burgess, 1988; Madge, 1997; Van Winsum-Westra and De Boer, 2004). 
Further research is required to investigate whether building size and deprivation in neighbourhoods in very strongly urban areas influence the relationship between green space and feelings of social safety.

A second result that requires further research is the finding that women and elderly people feel safer in living environments with more green space. Our findings cannot be explained by selective nonresponse, since the different age groups and both men and women are well represented and reasons given for refusing to participate were not related to the subject of the questionnaire.

Previous research has given clear indications that women and elderly people actually feel unsafe in green environments (eg Burgess, 1988; Jorgensen and Anthopoulou, 2007; Jorgensen et al, 2002; Koskela, 1997; Koskela and Pain, 2000; Madge, 1997), but the results of the present study indicate that green space in the living environment is associated with overall enhanced feelings of safety. Further research is required, therefore, to discover why women and the elderly feel safer in living environments with more green space.

\section{Strengths and limitations of the study}

This is the first study based on a large dataset to explore the relationship between the amount of green space in the living environment and feelings of social safety. The data on feelings of social safety and the land-use data were derived from different datasets; in consequence, there is no single-source bias. The data used for this study were not originally collected to measure the relationship between the amount of green space in people's living environment and feelings of social safety. Hence, we had to work with four-digit postcode sectors to calculate the percentage of green space-which might be regarded as a rather crude measurement. Data at the neighbourhood level or six-digit postcode level would perhaps have been better, but the necessary data were not available. However, Reijneveld et al (2000) found that the choice between data on neighbourhoods and postcode sectors hardly affected the outcomes in a study on small-area differences in health in the city of Amsterdam.

Although the data used for this study have several advantages, they also have a few shortcomings. First of all, our data on green space-although assessed on a small scale-do not take small green spaces in the living environment into account: only green space with a dominant position in the $25 \times 25 \mathrm{~m}$ grid cell was regarded as 'green space' in the dataset. Small bushes around a block of homes may be relevant to feelings of social safety, but could not be taken into account in this study. Secondly, our measure of feelings of social safety is rather general and not necessarily related to people's direct living environment. Furthermore, the questionnaire did not provide insight into where, at what time, and why people felt unsafe. Further research is required in which more specific questions, including questions on time and place, and qualitative approaches that contextualise and measure feelings of social safety in neighbourhoods with varying amounts of green space, should be used.

We were only able to look at a limited set of possibly confounding environmental characteristics in this study. Furthermore, no information was available on the quality of the green areas. Specific factors like maintenance of green areas, social cohesion, and sense of anonymity may shed more light on the negative effect of closed green spaces in very strongly urban areas, and should be taken into account in future research. Likewise, we could only investigate the relationship for some vulnerable groups (women and the elderly) in the population. Future studies should differentiate between ethnic groups, people with mental illnesses, disabled people, and lower socioeconomic groups, for example. Moreover, in this study we could not specify how large an area of green space is needed to enhance feelings of social safety, as the study provides insight only into the general relationship between the percentage of green space in the living 
environment and feelings of social safety. Future research should study in more detail how much green space is needed and the specific type of green space necessary.

Acknowledgement. This study was supported by a grant from the Netherlands Organisation for Scientific Research.

\section{References}

Amato P R, 1993, "Urban - rural differences in helping friends and family members" Social Psychology Quarterly 56 249-262

Burgess J, 1988, "People, parks and the urban green: a study of popular meanings and values for open spaces in the city" Urban Studies $25455-473$

Chivite-Matthews N, Maggs P, 2002, "Crime, policing and justice: the experience of older people. Findings from the British Crime Survey, England and Wales", Home Office, London, http://www.crimereduction.gov.uk/statistics25.htm

Den Dulk C J, Stadt D H, Vliegen J M, 1999, "Een nieuwe maatstaf voor stedelijkheid: de omgevingsadressendichtheid" [A new measurement for urbanisation: the environmental address density] Maandstatistiek van de bevolking 7 14-22

de Vries S, Verheij R A, Groenewegen P P, Spreeuwenberg P, 2003, "Natural environmentshealthy environments? An exploratory analysis of the relationship between green space and health" Environment and Planning A 351717 - 1731

de Wit A J W, Clevers J G P W, 2004, "Efficiency and accuracy of per-field classification for operational crop mapping" International Journal of Remote Sensing 254091 - 4112

Eck J E, Weisburd D, 1995, "Crime places in crime theory", in Crime and Place Eds J E Eck, D Weisburd (Criminal Justice Press, Monsey, NY) pp 1-33

Francis L J, 1999,'The benefits of growing up in rural England: a study among 13 - 15 year old females" Educational Studies 25(3) 335-341

Green G, Gilbertson J M, Grimsley M F J, 2002, "Fear of crime and health in residential tower blocks: a case study in Liverpool UK" European Journal of Public Health 1210 - 15

Hale C, Pack P, Salked J, 1994, "The structural determinants of fear of crime: an analysis using census and crime survey data from England and Wales" International Review of Victimology $3211-233$

Hanyu K, 2000, "Visual properties and affective appraisals in residential areas in daylight" Journal of Environmental Psychology $20273-284$

Herzog T R, Chernick K K, 2000, "Tranquility and danger in urban and natural settings" Journal of Environmental Psychology $2029-39$

Herzog T R, Flynn-Smith J A, 2001, "Preference and perceived danger as a function of the perceived curvature, length, and width of urban alleys" Environment and Behavior 33653 -666

Herzog T R, Kutzli G E, 2002, "Preference and perceived danger in fields/forest settings" Environment and Behavior $34819-835$

Jorgensen A, Anthopoulou A, 2007, "Enjoyment and fear in urban woodlands-does age make a difference" Urban Forestry and Urban Greening doi:10.1016/j.ufug.2007.05.004

Jorgensen A, Hitchmough J, Calvert T, 2002, "Woodland spaces and edges: their impact on perception of safety and preference" Landscape and Urban Planning 60135 - 150

Koskela H, 1997, “'Bold walk and breakings': women's spatial confidence versus fear of violence" Gender, Place and Culture 4301 - 321

Koskela H, Pain R, 2000, "Revisiting fear and place: women's fear of attack and the built environment" Geoforum 31269 - 280

Kuo F E, Sullivan W C, 2001a, "Aggression and violence in the inner-city. Effects of environment via mental fatigue" Environment and Behavior $33543-571$

Kuo F E, Sullivan W C, 2001b, "Environment and crime in the inner city: does vegetation reduce crime?" Environment and Behavior 33343 - 367

Kuo F E, Bacaicoa M, Sullivan W C, 1998, "Transforming inner-city landscapes. Trees, sense of safety, and preference" Environment and Behavior 3028 - 59

Little J, Panelli R, Kraack A, 2005, "Women's fear of crime: a rural perspective" Journal of Rural Studies 21151 - 163

LNV, 2004 Agenda Vitaal Platteland. Visiedocument. Inspelen op verandering [Agenda Vital Countryside.Vision document. Cater to changes], Ministry of Agriculture, Nature Management amd Fisheries (LNV), The Hague

Luymes D T, Tamminga K, 1995, "Integrating public safety and use into planning urban greenways" Landscape and Urban Planning $33391-400$ 
Maas J, Verheij R A, Groenewegen P P, De Vries S, Spreeuwenberg P, 2006, “Green space, urbanity and health: how strong is the relationship?" Journal of Epidemiology and Community Health $60587-592$

Madge C, 1997, "Public parks and the geography of fear" Tijdschrift voor Economische en Sociale Geografie $88237-250$

Mitchell R, Popham F, 2007, "Greenspace, urbanity and health: relationships in England" Journal of Epidemiological and Community Health $61681-683$

Müderrisoglu H, Demir Z, 2004, "The relationship between perceived beauty and safety in urban recreation parks" Journal of Applied Sciences $472-77$

Nasar J L, Fisher B, 1993, “'Hot spots' of fear and crime: A multi-method investigation” Journal of Environmental Psychology 13187 - 206

Nasar J L, Fisher B, Grannis M, 1993, "Proximate cues to fear of crime" Landscape and Urban Planning $26161-178$

Newman O, Franck K A, 1982, "The effects of building size on personal crime and fear of crime" Population and Environment $5203-220$

Nielsen T S, Hansen K B, 2007, "Do green areas affect health? Results from a Danish survey on the use of green areas and health indicators" Health and Place $13839-850$

Oc T, Tiesdell S, 1997 Safer City Centres: Reviving the Public Realm (Paul Chapman, London)

Oppelaar J, Wittebrood K, 2006, "Sociale veiligheid" [social safety], in Thuis op het platteland: de leefsituatie van platteland en stad vergeleken Eds C Steenbekkers, A Simon, V Veldheer (Sociaal en Cultureel Planbureau, Den Haag) pp 267-287

PMB, 2001 Politiemonitor Bevolking 2001, Landelijke rapportage" [Police population monitor, national report], Uitvoeringsconsortium Projectbureau Politiemonitor Den Haag/ Hilversum

Raudenbush S W, 2003, "The quantitative assessment of neighborhood social environments", in Neighborhood and Health Eds I Kawachi, L F Berkman (Oxford University Press, New York) pp $112-131$

Raudenbush S W, Sampson R J, 1999, "Ecometrics: toward a science of assessing ecological settings, with application to the systematic social observation of neighborhoods" Sociological Methodology $291-41$

Raudenbush S W, Rowan B, Kang S J, 1991, "A multilevel, multivariate model for studying school climate with estimation via the EM Algorithm and application to US high-school data" Journal of Educational Statistics 4295 - 330

Reijneveld S A, Verheij R A, de Bakker D H, 2000, "The impact of area deprivation in health: does choice of the geographical classification matter?" Journal of Epidemiology and Community Health $54306-313$

Sampson R J, Raudenbush S W, 1999, "Systematic social observation of public spaces: a new look at disorder in urban neighborhoods" American Journal of Sociology 105 603-651

South S J, Messner S F, 2000, "Crime and demography: multiple linkages, reciprocal relations" Annual Review of Sociology $2683-106$

Steenbekkers C, Simon A, Veldheer V, 2006 Thuis op het platteland: de leefsituatie van platteland en stad vergeleken [At home in the countryside: comparison of the living situation in the countryside with the city] Sociaal en Cultureel Planbureau, Den Haag

Takano T, Nakamura K, Watanabe M, 2002, “Urban residential environments and senior citizens' longevity in megacity areas. The importance of walkable green spaces" Journal of Epidemiology and Community Health 56913 - 918

Thunissen H A M, de Wit A J W, 2000, "The national land cover database of the Netherlands" ISPRS Journal of Photogrammetry and Remote Sensing $33223-230$

Valentine G, 1997, "A safe place to grow up? Parenting, perceptions of children's safety and the rural idyll” Journal of Rural Studies 13137 - 148

Van Winsum-Westra M, De Boer T A, 2004, "(On)veilig in bos en natuur? Een verkenning van subjectieve en objectieve aspecten van sociale en fysieke veiligheid in bos- en natuurgebieden" [(Un)safety in forests and nature? An exploration of subjective and objective aspects of social and physical safety in forest and nature areas], Alterra, University of Wageningen

Wilcox P, Quisenberry N, Jones S, 2003, "The built environment and community crime risk interpretation" Journal of Research in Crime and Delinquency 40322 - 345

Wittebrood K, Oppelaar J, 2005, "Criminaliteit" [Criminality], in De sociale staat van Nederland Sociaal en Cultureel Planbureau, Den Haag, pp 238-261 
Conditions of use. This article may be downloaded from the E\&P website for personal research by members of subscribing organisations. This PDF may not be placed on any website (or other online distribution system) without permission of the publisher. 